\title{
Sexual activity before and after total hip arthroplasty
}

\begin{abstract}
Introduction: Sexual life is an important component of the quality of life. However, it is a frequently neglected aspect in patients with hip osteoarthritis. The aim of the study was to evaluate the influence of total hip arthroplasty (THA) surgery on the quality of sexual life.

Methods: a retrospective study using an anonymous questionnaire administered to 270 patients in a face-to-face interview at physical medicine and rehabilitation department.

Results: The mean age when sexual difficulties began was 45 years (range: 21-63) two years after hip pain occurred. Sexual difficulties were considered severe to major by $19 \%$ of patients. The main causes of sexual difficulties were pain, then joint stiffness. Patients with the most pronounced and early sexual repercussions were young women with hip dysplasia. In patients' opinion, the implementation of THA improves sexual relations. The frequency of intercourse was increased after THA significantly, more frequently in women than in men, due to a change in coital position. Only $17 \%$ of patients had information about sexual activity before/after THA.
\end{abstract}

Conclusion: Sexual difficulties should not be marginalized, but should be assessed before and after surgery. It is the role of a multidisciplinary team: surgeon, physiatrist and physiotherapist as they should provide clear information.

Keywords: total hip replacement, sexual activity, patient information, quality of life
Volume I Issue 3 - 2017

\author{
Siham Zahi,' Laila Mahir,' Jalal Tounsi, ${ }^{2}$ Fatima \\ Lmidmani,' Mohammed Rafai, ${ }^{2}$ Mohammed \\ Rahmi, ${ }^{2}$ Abdelhaque El Garch, ${ }^{2}$ Abdellatif El \\ Fatimi' \\ 'Physical and rehabilitation medicine department, Ibn Rochd \\ Hospital, Africa \\ ${ }^{2}$ Traumatology Department, Ibn Rochd Hospital, Africa
}

Correspondence: Siham Zahi, Physical and rehabilitation medicine department, Ibn Rochd Hospital, Casablanca, Africa, Tel 002/2522482020/002/2522483030, Fax 00212522299483, Email zasil986@hotmail.com, drzahisiham@gmail.com

Received: April 19, 2017 | Published: June 23, 2017

\section{Introduction}

More than 1 million total hip arthroplasty (THA) is performed per year, and this number tends to double in the next 2 decades. ${ }^{1-3}$ The aim is to acquire indolence, mobility and improvement of quality of life. Sexual activity is an integral part of quality of life and affects it. ${ }^{4,5}$ Its dysfunction is strongly associated with physical and emotional dissatisfaction and depression. ${ }^{6}$ Restricted movement, pain and fear of dislocation will significantly affect sexual activity. We should notice that sexual problems themselves can be an indication to THA. ${ }^{7}$

THA improves significantly quality of life of individuals compared to patients not treated with severe hip osteoarthritis. ${ }^{8}$ Sexual satisfaction and performance's improvement were reported after successful THA in several studies. ${ }^{7,-11}$ However, it is clear that sexual activity's problem in patients with THA are underestimated and should be looked for by medical staff, even if patients do not ask explicitly. ${ }^{12}$ It was hoped that the data obtained would encourage better communication between patient and physician. Patients in general appear to be reluctant to discuss these issues, though many desire more information. ${ }^{7,10,11}$

For this we had four working hypotheses:

i. Chronic hip pain has a negative impact on sexual activity;

ii. THA improves quality of life;

iii. Patients voluntarily set limits, due to lack of knowledge, in the pre-postoperative period;

iv. This misunderstanding is largely due to a lack of information from the majority of the surgeons and / or caring teams.

\section{Methods}

In our study we used an anonymous questionnaire administered during a face-to-face interview from March 2013 to December 2016 at physical medicine and rehabilitation department of IBN ROCHD University Hospitals. Inclusion criteria were a married status, an age of $\leq 65$ years at the time of the study and primary THA of more than 6 months before the beginning of the study. Exclusion criteria included severe comorbidities, not having sexual activities during the previous period due to other reasons not related to hip's problem. The patients with a history of postoperative complications (deep infection, fracture, dislocation, or revision for any reason) were also excluded. The surgery was performed by the same team of surgeon using only a posterolateral approach. Our questionnaire took up the items devised by Currey ${ }^{11} \&$ Meyer et al., ${ }^{13}$ associated with the functional scale of Womac. ${ }^{14}$ To facilitate interpretation, the proposed responses to the Currey questionnaire were adapted to the five-point Lickert scale by placing a cross in one of the boxes (none, minimal, moderate, important, major) corresponding to the scores of $0,1,2,3$ and 4 . The most comfortable pre-operative and post-operative sexual positions were investigated among the 12 postures used in the article reported by Dahm et al. ${ }^{15}$ Statistical analysis was performed using Statview ${ }^{\circledR}$ software (Version 5.0, California, United States). The quantitative variables were compared using the Wilcoxon nonparametric test or the Mann-Whitney U test. The Chi-2 test or the exact test of Fischer were used for the comparison of variables qualitative. The threshold of statistical significance was $p$ of less than 0.05 .

\section{Results}

We had 270 patients who undergone THA, 116 women and 154 men. The clinical and demographic characteristics of patients are summarized in Table 1. The mean age when sexual difficulties started was 45 years (range: $21-63$ ) two years after hip pain occurred (Table 2). Sexuality is altered earlier with statistical significance in hip dysplasia compared to primary hip osteoarthritis $(\mathrm{p}=0.003)$, aseptic osteonecrosis $(p=0.03)$ and secondary hip osteoarthritis $(p=0,07)$. 
Hip dysplasia, which mainly affects young women, has earliest sexual repercussion, while primary hip osteoarthritis is the one with later sex repercussion. of those patients with sexual difficulties, the most common reason given was a hip/back pain (37.4\%), followed by a limitation of motion (36.3\%) (Table 3 ). Preoperatively, women were significantly more sexually disabled than men $(\mathrm{p}=0.004)$ (Table 4). But postoperatively, there were no differences $(p=0.13)$. Sexual difficulties were behind patient's decision to undergo THA only in $18.5 \%$ of patients. This percentage reaches $36 \%$ in patients with hip dysplasia.Mean time to resumption of sexual activity was 66.5 days (range: 4-365) after THA. 5 patients never resume sexual activity. It occurred significantly later in women (87 days) than men (54 days, $\mathrm{p}=0.0005$ ). Diagnosis had no impact on this delay. Number of patients without sexual difficulties or minimal difficulties was $54 \%$ before THA and $74 \%$ after THA. After THA, the frequency of sexual activity increased in $18.5 \%$ of patients specially women $(\mathrm{p}=0.02)$, decreased in $11.5 \%$ of patients and did not change in $70 \%$ of patients. Only women with little or no sexual difficulties had a significantly lower functional score of Womac than those with moderate sexual difficulties $(2,6 / 28$ versus $6,8 / 28, \mathrm{p}=0,002$ ) (Table 5).

Men used the same coital position (No. 5, 7, 8 in descending order) before and after THA, but women's coital position was different before and after THA (89\%). They preferred coital position that did not require abduction and external rotation of hip before THA (No. 7, 8,3 in descending order). The most troubling problem during sexual activity was the fear of dislocation. Only $17.3 \%$ of patients were able to obtain information on sexual activity before and / or after THA, and only $10.5 \%$ were aware of the time needed for resumption. In most cases, this information was taken from internet $(13,5 \%)$, followed by medical staff (3,8\%): physiotherapist and physiatrist in charge of rehabilitation. Patients felt that it was the surgeon, followed by the physiatrist and then the physiotherapist, who were best placed to deliver this type of information and that a booklet would be a good way to supplement this information (Table 6). Of the 223 patients who did not ask a physician for information, 201 patients $(90.2 \%)$ responded that the topic was too personal to discuss, and 22 patients $(9.8 \%)$ cited an unsuitable environment in outpatient clinics. The question that most patients wanted answered concerned the safety of coital positions and the second most common question concerned the time of resumption.

Table I Demographic Factors of the patients

\begin{tabular}{ll}
\hline Characteristic & No. of patients (\%) \\
\hline Sex & $154(57 \%)$ \\
Male & $116(43 \%)$ \\
Female & $51,5(21-65)$ \\
Age (average, min-max) & \\
Time after total hip replacement & $78(28,8 \%)$ \\
6 mo-I yr & $97(36 \%)$ \\
I-2 yr & $95(35,2 \%)$ \\
$>2$ yr & \\
Diagnosis & $98(36,3 \%)$ \\
Osteonecrosis of femoral head & $112(41,5 \%)$ \\
primary hip osteoarthritis & $18(6,7 \%)$ \\
secondary hip osteoarthritis & $30(11,1 \%)$ \\
hip dysplasia & $12(4,4 \%)$ \\
Rheumatoid arthritis & \\
\hline
\end{tabular}

Table 2 Mean age (range) related to hip pain/sexual difficulties beginning (year) and time for intercourse resumption postarthroplasty (day)

\begin{tabular}{lllllll}
\hline & $\begin{array}{l}\text { Total } \\
\text { (min-max) }\end{array}$ & $\begin{array}{l}\text { Osteonecrosis of } \\
\text { femoral head }\end{array}$ & $\begin{array}{l}\text { Primary hip } \\
\text { osteoarthritis }\end{array}$ & $\begin{array}{l}\text { Secondary hip } \\
\text { osteoarthritis }\end{array}$ & $\begin{array}{l}\text { Hip } \\
\text { dysplasia }\end{array}$ & $\begin{array}{l}\text { Rheumatoid } \\
\text { arthritis }\end{array}$ \\
\hline Age of hip pain beginning & $42,6(9-65)$ & $41,5(18-56)$ & $45,6(20-65)$ & $36,0(9-60)$ & $33,3(9-52)$ & $43,7(33-52)$ \\
$\begin{array}{l}\text { Age of sexual difficulties } \\
\text { beginning }\end{array}$ & $45(21-63)$ & $42,2(21-58)$ & $49,4(28-65)$ & $45,3(30-61)$ & $33,3(24-52)$ & $39,5(36-43)$ \\
$\begin{array}{l}\text { time for intercourse } \\
\text { resumption postarthroplasty }\end{array}$ & $66,4(4-365)$ & $61,8(5-210)$ & $69,9(8-365)$ & $62,4(4-180)$ & $\begin{array}{l}75,5(21- \\
120)\end{array}$ & $45,7(35-60)$ \\
\hline
\end{tabular}

Table 3 Reasons for preoperative sexual difficulties

\begin{tabular}{ll}
\hline Hip/back pain & $\mathbf{1 0 1 ( 3 7 , 4 \% )}$ \\
\hline Range of motion limitation & $98(36,3 \%)$ \\
Loss of libido & $21(7,7 \%)$ \\
Variable & No. of patients $(\%)$ \\
Lack of understanding from the spouse & $9(3,3 \%)$ \\
None & $41(15,3 \%)$ \\
\hline
\end{tabular}

${ }^{a}$ The total is less than 270 due to non-response 
Table 4 Gender effect in sexual difficulties' reasons and total hip replacement's result

\begin{tabular}{|c|c|c|c|}
\hline Variable & Male & Female & $\mathbf{P}$ \\
\hline NO. & 154 & 116 & \\
\hline \multicolumn{3}{|c|}{ Sexual difficultiesbehind patient'sdecision to undergo THA a } & 0,33 \\
\hline Yes & $18(11,6 \%)$ & $24(20,7 \%)$ & \\
\hline No & $106(68,8 \%)$ & $78(73,6 \%)$ & \\
\hline Preoperative sexual difficulties a & & & 0,004 \\
\hline None & $62(40,2 \%)$ & $16(15,1 \%)$ & \\
\hline Slight & $36(23,4 \%)$ & $22(20,7 \%)$ & \\
\hline Moderate & $38(24,7 \%)$ & $44(41,5 \%)$ & \\
\hline Severe & $16(10,4 \%)$ & $28(26,4 \%)$ & \\
\hline Major & $2(1,3 \%)$ & $6(5,6 \%)$ & \\
\hline \multicolumn{4}{|l|}{ Reasons for sexual difficulties } \\
\hline Hip/back pain & $39(25,3 \%)$ & $62(58,5 \%)$ & \\
\hline Range of motion limitation & $32(20,8 \%)$ & $66(62,3 \%)$ & \\
\hline Loss of libido & $8(5,2 \%)$ & $13(12,3 \%)$ & \\
\hline Lack of understanding from the spouse & $7(4,5 \%)$ & $2(1,9 \%)$ & \\
\hline Postoperative sexual difficulties a & & & 0,13 \\
\hline None & $58(37,6 \%)$ & $36(33,9 \%)$ & \\
\hline Slight & $22(14,3 \%)$ & $16(15,1 \%)$ & \\
\hline Moderate & $16(10,4 \%)$ & $30(28,3 \%)$ & \\
\hline Severe & 0 & 0 & \\
\hline Major & 0 & $2(1,9 \%)$ & \\
\hline \multicolumn{3}{|c|}{ Sexual intercourse frequency after total hip replacement a } & 0,02 \\
\hline Stationary & $122(79,2 \%)$ & $60(56,6 \%)$ & \\
\hline Increased & $16(10,4 \%)$ & $32(30,2 \%)$ & \\
\hline decreased & $16(10,4 \%)$ & $14(13,2 \%)$ & \\
\hline $\begin{array}{l}\text { Time course for the resumption of intercourse } \\
\text { postarthroplasty }\end{array}$ & $53,9(5-210)$ & $87,2(4-365)$ & 0,0005 \\
\hline
\end{tabular}

Table 5 Reduction of the Womac functional score according to sex and sexual difficulties

\begin{tabular}{llll}
\hline & Sexual difficulties absent or minimal & Moderate sexual difficulties & P \\
\hline Male & $2,9 \pm 4,2(0-19)$ & $3,3 \pm 4,6(0-14)$ & $0,8 \mid$ \\
Women & $2 \pm 2,4(0-7)$ & $9,2 \pm 5,7(0-20)$ & 0,0002 \\
\hline
\end{tabular}

Table 6 Patient's preferences for source of information on sexuality related to his / her disease and surgery

\begin{tabular}{|c|c|c|c|c|c|}
\hline & Certainly yes & Yes & Certainly no & no & Uncertain \\
\hline Surgeon & 119 & 75 & $\mathrm{II}$ & 25 & 40 \\
\hline Physiatrist & 79 & 91 & 10 & 30 & 60 \\
\hline Physiotherapist & 71 & 87 & 9 & 40 & 63 \\
\hline Nurse & 19 & 35 & 52 & 69 & 145 \\
\hline Booklet & 120 & 80 & 15 & 10 & 45 \\
\hline
\end{tabular}




\section{Discussion}

Our study confirmed our hypotheses about the adverse effects of chronic hip pain on sexual activities of our patients. Several studies showed that more than half of the patients suffer from sexual difficulties directly related to chronic hip pain, ${ }^{10,11}$ and in 5 to $10 \%$ patients, it caused sexual intercourse's cessation. ${ }^{9-11}$ The main causes are pain, apprehension of pain, asthenia and joint stiffness. ${ }^{9,16}$ Other factors may be involved, ${ }^{11,16,17}$ decreased libido, involvement of other joints, such as those of rachis, ${ }^{18}$ which is observed early in chronic inflammatory rheumatism in young subjects. ${ }^{19}$

Women are affected more often than men by these sexual difficulties, in term of frequency, intensity and age of illness. ${ }^{9-11}$ In these cases, THA usually ameliorates these symptoms. ${ }^{9,19}$ Stern et al. ${ }^{9}$ demonstrate that frequency of sexual intercourse after THA increase so it proves beneficial effects of surgery on patients' sexuality. Our study confirms these results, but frequency increases only in less than $20 \%$ of our patients.

In our study, the median time to resumption of sexual activity was more than two months. Men seemed to resume their sexual activities earlier than women because they need less joint mobility. We also found that men used the same coital positions before and after THA. However, in women the coital positions are very different between the preoperative period, where the chosen positions require a low joint mobility, and the period after surgery where positions with abduction and external rotation in supine position are preferred. The most common fear during sexual activity was dislocation. These coital positions can be used early without risk. It is necessary to respect a period of one month to allow the healing of periarticular tissues (especially posterior stabilizing elements), skin and subcutaneous tissue. Sexual intercourse can be safely resumed after a postoperative period of one to two months ${ }^{9}$ for the supine position and after three months whatever the position except extreme coital position. There is a lack of information about sexual difficulties induced by chronic hip diseases. ${ }^{7,9-11,13,15}$ Dahm et al. ${ }^{15}$ emphasize that $80 \%$ of physicians rarely, if never, talk about sexuality after THR with their patients. More than three-quarters of patients would like information about sexual intercourse after THR to be delivered, and two-thirds feel that a dialogue with the surgeon would help them. ${ }^{11}$ In our study, most patients were unable to obtain information, and did not ask for due to the personal nature of the topic. The internet was the most common source of information among those who managed to obtain information on sexual activity. However, studies on the quality of medical information provided by internet show that it is often misleading and of poor quality, which means that patients may be provided with incorrect information. ${ }^{20-23}$ In the early postoperative period, the role of the surgeon, the physiotherapist and then the rehabilitation doctor must be to reassure patients of their possibilities while providing them with clear and detailed information to limit the risk of dislocation during activities of everyday life as well as during sexual activities. The information must relate to resumption's period of sexual activities and permissible coital positions without risk of complication. A simple and clear information booklet would facilitate the dialogue between the medical staff and the patient. This article has some limitations which are inherent in this type of study. First, the retrospective nature of this study means it is limited by the patient recall. Second, personal face-to-face interviews may distort information, especially when the questions address sensitive issues. $^{24,25}$ The anonymous character allows patients to express more freely on a private subject. ${ }^{4,10}$ The impact of sexual difficulties on quality of life, tension or dissatisfaction in relationship with the partner is more easily expressed anonymously.

\section{Conclusion}

Chronic hip pain has a negative impact on sexual activity. THA improves quality of sexual life. With the current knowledge, an effort should be made to assess sexual difficulties before and after surgery and to not be marginalized. These efforts should focus on improved education of patients, particularly women. It is the role of a multidisciplinary team: surgeon, physiatrist and physiotherapist. A clear information should be provided even not asked explicitly.

\section{Acknowledgements}

None.

\section{Conflict of interest}

The author declares no conflict of interest.

\section{References}

1. Mancuso CA, Salvati EA, Johanson NA, et al. Patients' expectations and satisfaction with total hip arthroplasty. J Arthroplasty. 1997;12(4):387396.

2. Cacko MA, Keener JD. Chapter 67 Total hip arthroplasty. In: Placzek JD, Boyce DA, editors. Orthopaedic physical therapy secrets. 2nd ed. Saint Louis: Mosby; 2006. p. 539-543.

3. Siguier T, Siguier M, Brumpt B. Mini-incision anterior approach does not increase dislocation rate: A study of 1037 total hip replacements. Clin Orthop Relat Res. 2004;426:164-173.

4. Marwick C. Survey says patients expect little physician help on sex. JAMA. 1999;281(23):2173-2174.

5. Stock SR, Cole DC, Tugwell P, et al. Review of applicability of existing functional status measures to the study of workers with musculoskeletal disorders of the neck and upper limb. Am J Ind Med. 1996;29(6):679688 .

6. Laumann EO, Paik A, Rosen RC. Sexual dysfunction in the United States: prevalence and predictors. JAMA. 1999;281(6):537-544.

7. Baldursson $H$, Brattstrom $H$. Sexual difficulties and total hip replacement in rheumatoid arthritis. Scand J Rheumatol. 1979;8(4):214-216.

8. Mariconda M, Galasso O, Costa GG, et al. Quality of life and functionality after total hip arthroplasty: A long-term follow-up study. BMC Musculoskelet Disord. 2011;12:222.

9. Stern SH, Fuchs MD, Ganz SB, et al. Sexual function after total hip arthroplasty. Clin Orthop Relat Res. 1991;269:228-235.

10. Todd RC, Lightowler CD, Harris J. Low friction arthroplasty of the hip joint and sexual activity. Acta Orthop Scand. 1973;44:690-693.

11. Currey HL. Osteoarthrosis of the hip joint and sexual activity. Ann Rheum Dis. 1970;29(5):488-493.

12. Laffosse JM, Tricoire JL, Chiron P, et al. Sexual function before and after primary total hip arthroplasty. Joint Bone Spine. 2008;75:189-194.

13. Meyer H, Stern R, Fusetti C, et al. Sexual quality-of-live after hip surgery. Journal of Orthopaedics and Traumatology. 2003;4(1):21-25.

14. Whitehouse S, Lingard E, Katz J, et al. Development and testing of a reduced Womac function scale. J Bone Joint Surg Br. 2003;85:706-711. 
15. Dahm D, Jacofsky D, Lewalleen D. Surgeons rarely discuss sexua activity with patients after THA. Clin Orthop. 2004;428:237-240.

16. Schover L, Buus Jensen S. Sexuality and chronic illness. USA: The Guilford Press; 1988.

17. Ambler N, Williams A, Hill P, et al. Sexual difficulties of chronic pain patients. Clin J Pain. 2001;17(2):138-145.

18. Kahn M, Brissaud P, Dreiser R. Vie sexuelle et rhumatismes. L'actualité rhumatologique. 2003. p. 189-199.

19. Ozgul A, Peker F, Taskaynatan M, et al. Effect of ankylosing spondylitis on health-related quality of life and different aspects of social life in young patients. Clin Rheumatol. 2006;25(2):168-174.

20. Bell DS, Fonarow GC, Hays RD, et al. Self-study from web-based and printed guideline materials: a randomized, controlled trial among resident physicians. Ann Intern Med. 2000;132(12):938-946.
21. Beredjiklian PK, Bozentka DJ, Steinberg DR, et al. Evaluating the source and content of orthopaedic information on the Internet: the case of carpal tunnel syndrome. J Bone Joint Surg Am. 2000;82(11):1540-1543.

22. Moshirfar A, Campbell JT, Khasraghi FA, et al. Evaluating the quality of Internet-derived information on plantar fasciitis. Clin Orthop Relat Res. 2004;421:60-63.

23. Soot LC, Moneta GL, Edwards JM. Vascular surgery and the Internet: a poor source of patient-oriented information. J Vasc Surg. 1999;30(1):84 91

24. Gribble JN, Miller HG, Rogers SM. Interview mode and measurement of sexual behaviors: methodological issues. J Sex Res. 1999;36(1):16-24.

25. Tourangeau R, Yan T. Sensitive questions in surveys. Psychol Bull. 2007;133(5):859-883. 